\title{
Profile of COVID-19 Patients in Dr. Moewardi Hospital Surakarta Indonesia
}

\author{
Cahyono Hadi ${ }^{1,2}$, Cipta Pramana ${ }^{3,4 *}$ (D) \\ ${ }^{1}$ Department of Obstetrics and Gynecology, Faculty of Medicine, Public Health and Nursing, Gadjah Mada University, \\ Yogyakarta, Indonesia; ${ }^{2}$ Dr. Moewardi Hospital Surakarta, Surakarta, Indonesia; ${ }^{3}$ Medical Faculty, Tarumanagara University, \\ Jakarta, Indonesia; ${ }^{4}$ Department of Obstetrics and Gynecology, K.R.M.T. Wongsonegoro Hospital, Semarang, Indonesia
}

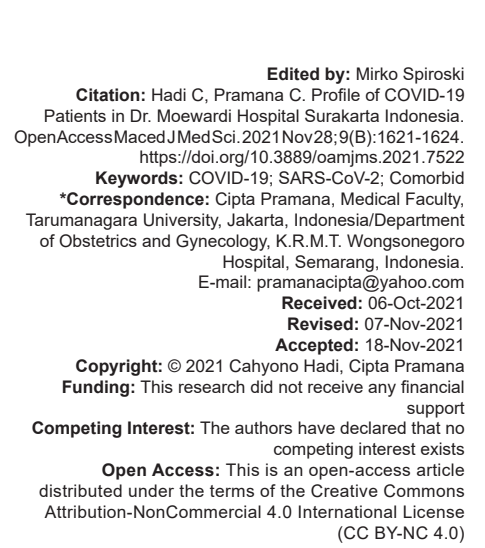

Abstract

BACKGROUND: The 2019 coronavirus disease has been declared by the World Health Organization as a pandemic that has spread throughout the world since March 2020.

AIM: This study was conducted to determine the profile of COVID-19 patients at RSUD Dr. Moewardi Surakarta.

METHODS: This study is a retrospective descriptive study, with the population and study samples taken from medical records of patients with a diagnosis of COVID-19 or SARS-CoV-2.

RESULTS: Male sex with a total of 42 patients (47.72\%) and female sex 46 patients $(52.57 \%)$. The highest age group was in the age group of $40-59$ years with 46 patients $(52.27 \%)$, with the most comorbid history being cardiovascular disease 31 patients $(35.22 \%)$. The mean of cytokine analysis of 88 patients which included interleukin (IL)-1 examination was 73.95 and tumor necrosis factor (TNF) - with an average of 67.19. The mean shows an increase above the normal value.

CONCLUSION: There is no difference between male and female gender. The highest age range is in the 40-59-year age group. The most common comorbid history is cardiovascular disease. And the average patient showed increased levels of IL- 1 and TNF- $\alpha$.

\section{Introduction}

The novel coronavirus (2019-nCoV) was first reported by the Chinese government to the World Health Organization (WHO) on Friday, December 31, 2019. This virus was found in pneumonia patients who came from Wuhan, Hubei Province, China. This virus can be transmitted from infected humans to other people. And 2019-nCoV has an incubation time of between 2 and 14 days, during which the incubation person is potentially infected with or without symptoms. The WHO organization declared the SARS-CoV-2 infection which was later referred to as COVID-19 as a pandemic on March 11, 2020 [1], [2]. To avoid transmission is to maintain physical distance, maintain social distance, and use masks. At the beginning of a pandemic, the best strategy to reduce the spread of SARS-CoV-2 in some countries is the use of masks and city disinfection [3]. And another best way to fight against a pandemic, everyone must keep their immune system healthy. One way to strengthen the immune system is by consuming nutritious foods and examples of diets rich in zinc such as fruits, vegetables, nuts, and seeds that will improve the quality of public health [4]. Viruses, epidemics, and pandemics are negative phenomena to human survival. Among the emerging phenomena are increased morbidity and mortality, decreased productivity, and their impact on the economic stability of the community [5].

As of September 14, 2021, COVID-19 has affected more than 225 million people across the country, with the death of a population of 4.6 million [6], [7]. Laboratory studies show that SARS-CoV-2 is cytopathic and it can cause lung injury as indicated by pathological examination. The pathophysiology includes viral amplification, the host immune response becomes activated, which clears the virus and heals the patient. We suspect that cytokine storms play an important role in the pathogenesis of severe COVID-19 cases [8].

Several complications are associated with COVID-19 infection, increasing the morbidity and mortality rates. The previous research has identified that weak health systems and failures in prevention are contributing factors to high infection rates, especially in poor, and developing countries. A high risk of severity and death has been widely reported in older people infected with COVID-19, a finding that is consistent in several countries. Surgical procedures especially transplantation and pre-existing comorbidities, such as hypertension, obesity, diabetes mellitus, cardiovascular 
disease, respiratory disease, malignancy, and other chronic non-communicable diseases have been reported to worsen clinical outcomes in COVID-19 patients, thus increasing the ratio of death [9].

The overall proportion of diabetes in COVID-19 patients was from $7.4 \%$ to $20 \%$. Data on the immune and inflammatory response to COVID-19 in diabetic patients are limited at this time. Increased inflammatory susceptibility and increased disease severity were observed in COVID-19 patients with diabetes, which was associated with increased care in the intensive care unit (ICU). Cytokine storms are often associated with dysregulation of glucose metabolism, resulting in metabolic and energy failure. Hyperglycemia is thought to deliver glucose to leukocytes without insulin support; therefore, glucose uptake from leukocytes may not be affected in patients with insulin resistance or insulin deficiency [6].

Cytokines are known as inflammatory mediators that increase the inflammatory response, such as tumor growth factor (TNF)-beta, gamma interferon (IFN-), interleukin (IL)-1, IL-8, IL-6, and TNF- $\alpha$, while several other cytokines function to reduce inflammation such as IL-4 and IL-10. In the early stages of SARS, low T lymphocyte counts, especially in severe cases, indicate altered immunomodulatory function. Therefore, it is important to analyze the cytokine load in the serum of patients with COVID-19, compared to healthy and recovered individuals to decipher the cellular mechanisms behind the pathogenesis of the coronavirus [10]. The purpose of this study was to determine the profile of COVID-19 patients at Dr. Moewardi hospital Surakarta Indonesia, period April 2020 - June 2020.

\section{Methods}

This study is a retrospective descriptive study, with the population and research samples taken from medical records of patients with a diagnosis of COVID-19 or SARS-Cov-2 who were treated in isolation wards and negative pressure ICUs at RSUD Dr. Moewardi Surakarta in the period April 2020 - June 2020. Patients aged 13-88 years, male and female, with data on comorbid history, smoking habits, body mass index, disease degree, length of treatment, IL-1 examination, TNF $-\alpha$, and the condition when leaving the hospital distribution of lesions, comorbid disease, and type of therapy. The inclusion criteria of this study were samples with complete medical record data and the study exclusion criteria were sampled with incomplete medical record data.

\section{Results}

Demographic characteristics based on Table 1 show male sex with a total of 42 patients (47.72\%) and female sex with a total of 46 patients $(52.57 \%)$. The highest age group was the age group 40-59 years with a total of 46 patients $(52.27 \%)$, with the most comorbid history being cardiovascular disease as many as 31 patients $(35.22 \%)$.

Table 1: Demographic characteristics of COVID-19 patients at Dr. Moewardi Hospital Surakarta April 2020 - June 2020

\begin{tabular}{|c|c|c|}
\hline Characteristics & Total $(n=88)$ & Percentage \\
\hline \multicolumn{3}{|l|}{ Gender } \\
\hline Man & 42 & 47.72 \\
\hline Woman & 46 & 52.27 \\
\hline \multicolumn{3}{|l|}{ Age (years old) } \\
\hline $1-17$ & 1 & 1.13 \\
\hline $18-39$ & 15 & 17.04 \\
\hline $40-59$ & 46 & 52.27 \\
\hline$>60$ & 26 & 29.54 \\
\hline \multicolumn{3}{|l|}{ Comorbid history } \\
\hline Cardiovascular* & 31 & 35.22 \\
\hline $\begin{array}{l}\text { Immunity } \\
\text { disorders }\end{array}$ & 2 & 2.27 \\
\hline Malignancy & 9 & 10.22 \\
\hline \multicolumn{3}{|l|}{ Habit history } \\
\hline Smoke & 28 & 31.81 \\
\hline Do not smoke & 60 & 68.18 \\
\hline \multicolumn{3}{|l|}{ Body mass index } \\
\hline $\begin{array}{l}<18.5 \\
\end{array}$ & 1 & 1.13 \\
\hline $18.5-23$ & 31 & 35.22 \\
\hline $23-27.5$ & 51 & 57.95 \\
\hline$>27.5$ & 5 & 5.68 \\
\hline
\end{tabular}
and peripheral arterial-venous disease.

Some patients had a history of smoking lower than the group of patients who did not smoke (28 and 60 patients). Patients with the highest body mass index were in the BMI group of 23 - 27.5 (overweight) with a total of 51 patients $(57.95 \%)$.

Table 2: Criteria for Symptoms and Treatment of COVID-19 Patients at Dr. Moewardi Hospital Surakarta April 2020 - June 2020

\begin{tabular}{lll}
\hline Characteristic & Total $(\mathrm{n}=88)$ & Percentage \\
\hline $\begin{array}{l}\text { Symptom criteria } \\
\text { Light }\end{array}$ & 26 & \\
$\quad$ Currently & 36 & 29.54 \\
$\quad$ Heavy & 20 & 40.90 \\
$\quad$ Critical & 6 & 22.72 \\
Ward & & 6.81 \\
$\quad$ Non-intensive ward & 61 & 69.32 \\
$\quad$ Intensive ward & 27 & 30.68 \\
Count leukocytes & & \\
$\quad$ Leukopenia (Low white blood cell count) & 11 & 12.50 \\
$5-11 \times 10^{3} / \mathrm{mm}^{3}$ & 51 & 57.95 \\
$\quad 11.1-17 \times 10^{3} / \mathrm{mm}^{3}$ & 16 & 18.18 \\
$>17 \times 10^{3} / \mathrm{mm}^{3}$ & 15 & 17.04 \\
Platelet count & & \\
$\quad<150 \times 10^{9} / \mathrm{L}$ & 16 & 18.18 \\
$>150 \times 10^{9} / \mathrm{L}$ & 72 & 81.82 \\
When blood sugar (mg/dL) & & 87.50 \\
$\quad<200$ & 77 & 12.50 \\
$>200$ & 11 & \\
\hline
\end{tabular}

The criteria for symptoms, treatment, and the results of leukocyte and platelet counts are shown in Table 2. Patients with a diagnosis of COVID-19 disease were classified at the beginning of treatment into patients with mild, moderate, severe, and critical symptoms. Patients with moderate initial symptoms were the most admitted patients with 36 patients (22.72\%), followed by mild symptoms 26 patients $(29.54 \%)$, severe symptoms 
20 patients $(22.72 \%)$, and critical symptomatic patients six patients $(6,81 \%)$. Patients were treated in non-intensive isolation rooms as many as 61 patients $(69.32 \%)$ and in negative pressure intensive isolation rooms as many as 27 patients (30.68\%).

The criteria for symptoms, treatment, and the results of leukocyte and platelet counts are shown in Table 2. Patients with a diagnosis of COVID-19 disease were classified at the beginning of treatment into patients with mild, moderate, severe, and critical symptoms. Patients with moderate initial symptoms were the most admitted patients with 36 patients $(22.72 \%)$, followed by mild symptoms 26 patients (29.54\%), severe symptoms 20 patients $(22.72 \%)$, and critical symptomatic patients six patients $(6,81 \%)$. Patients were treated in non-intensive isolation rooms as many as 61 patients $(69.32 \%)$ and in negative pressure intensive isolation rooms as many as 27 patients (30.68\%).

The results of recording the peripheral blood examination showed the value of leukocyte and platelet counts in the patients in Table 2. Patients with leukopenia were 11 patients (12.50\%), leukocytes with normal ranges were 51 patients (57.95\%), leukocytosis 16 patients $(18.18 \%)$, and severe leukocytosis $\left(>17 \times 10^{3} / \mathrm{mm}^{3}\right)$ in 15 patients $(17.04 \%)$. Patients with thrombocytopenia (<150 × 10\% /L) were 16 patients and patients with more normal range platelets were 72 patients (81.82\%). Examination of blood sugar at the time showed 11 patients with blood sugar levels above $200 \mathrm{mg} / \mathrm{dL}(12.50 \%)$ and blood sugar levels below $200 \mathrm{mg} / \mathrm{dL}$ as many as 77 patients (87.50\%).

Table 3 shows the mean cytokine analysis of 88 patients which includes IL-1 examination which is 73.95 and TNF- $\alpha$ with an average of 67.19 . The mean shows an increase above the normal value.

Table 3: Mean analysis of serum IL-1 and TNF- cytokines during treatment $(n=88)$

\begin{tabular}{ll}
\hline $\mathrm{IL}-1(\mathrm{pg} / \mathrm{L})$ & TNF- $\alpha(\mathrm{ng} / \mathrm{L})$ \\
\hline 73.95 & 67.19 \\
\hline
\end{tabular}

\section{Discussion}

In this study, from April to June 2020, a total of complete medical records of patients with a diagnosis of COVID-19 and SARS-COV-2 have obtained as many as 88 patients with a male to female ratio of $0.9: 1$. This indicates that there is no significant difference between the sex predictors, with the same risk of exposure.

Patients aged 40-59 years are the group most infected with COVID-19, due to the high mobility of patients in that age range. According to Liu's research
(2020), age is a strong predictor where increasing age will exacerbate symptoms and patient treatment outcomes. Critically ill patients had a mean age of 70 years compared to patients with moderate symptoms at a mean age of 55 years [11], [12].

Chronic comorbidities take several forms in infectious disorders, such as a prolonged pro-inflammatory state and innate and adaptive immune dysfunction, which may be the main drivers of poorer clinical outcomes in patients infected with SARS-CoV-2. In particular, Angiotensin Converter Enzyme 2 (ACE2), which is expressed in lung and cardiac tissue, has been identified as an important functional receptor for SARS-CoV-2 invasion. In patients with obesity, diabetes, or CVD, ACE2 expression has been found to be upregulated, thereby increasing susceptibility to SARS-CoV-2 infection and the risk of disease worsening [13]. Research by Fathi et al. (2020) also stated that obesity and increased BMI correlated with an increased risk of worsening in patients with COVID-19 infection [14].

The results showed that the average number of COVID-19 patients who were treated from April to June 2020 had relatively normal leukocyte and platelet counts. The leukocyte count value was found to be normal, but according to Liu's (2020) study, the leukocyte count was divided into neutrophil count and lymphocyte count where an increase in neutrophils and a decrease in lymphocytes correlated with an increase in intensive care. Patients with low platelet counts also correlated with a more severe increase in COVID-19 symptoms [11], [15].

IL, IFN, TNF, and colony-stimulating factors (CSFs) are the main cytokines involved in the formation of cytokine storms during COVID-19. Several studies have suggested a significant role of various proinflammatory factors such as IL-2, 6, 8, 10, 1 $\beta$, TNF, IFN, and Granulocyte-macrophage colony-stimulating factors. In the prognosis of COVID-19 disease [16], the mean patients in Table 3 show an above-normal increase in IL-1 and TNF- levels indicating the presence of various cytokines triggered by COVID-19 infection. It is suspected that the increased production of cytokines will exacerbate the COVID-19 condition due to endothelial cell activation, endothelial dysfunction, and thrombosis [17].

\section{Conclusion}

This study is a description of COVID-19 patients at RSUD Dr. Moewardi in the period April 2020-June 2020 with a total of 88 patients. There is no difference between male and female gender. The highest age range was in the 40-59-year age group, as many as 46 patients. Age, history of comorbidities, body 
mass index, peripheral blood examination, $\mathrm{IL}-1$, and TNF- cytokine examination were recorded in the patient's care. The profile of COVID-19 patients in this period may differ in other regions but shows a similar correlation with previously reported studies.

\section{References}

1. Pramana C, Herawati S, Santi N, Rosreri, Maryani LP, Dachliana OR. The first case of COVID-19 in Semarang, Indonesia: Acase report. Int J Pharm Res. 2020;12(2):1875-1878.

2. WHO. WHO Director-General's Opening Remarks at the Media Briefing on COVID-19-11 March 2020; 2020. Available from: https://www.who.int/director-general/speeches/detail/ who-director-general-s-opening-remarks-at-the-mediabriefing-on-covid-19---11-march-2020 [Last accessed on 2020 Mar 11].

3. Telles CR, Roy A, Ajmal MR, Mustafa SK, Ahmad MA, de la Serna JM, et al. The impact of COVID-19 management policies tailored to airborne SARS-CoV-2 transmission: Policy analysis. JMIR Public Health Surveill. 2021;7(4):e20699. https:// doi.org/10.2196/20699

PMid:33729168

4. Syed Khalid M, Aljohani MM, Alomrani NA, Oyoun AA, Alzahrani O, Ahmad MA, et al. COVID-19 and immune function-"a significant" Zinc. Orient J Chem. 2020;36(6):1026-36.

5. Mustafa SK, Ahmad MA, Baranova V, Deineko Z, Lyashenko V. Using wavelet analysis to assess the impact of COVID-19 on changes in the price of basic energy resources. Int $\mathrm{J}$ Emerg Trends Eng Res. 2020;8(7):2907-12.

6. Zheng M, Wang X, Guo H, Fan Y, Song Z, Lu Z, et al. The cytokine profiles and immune response are increased in COVID-19 patients with Type 2 diabetes mellitus. J Diabetes Res. 2021;2021:9526701. https://doi.org/10.1155/2021/9526701 PMid:33490288

7. Siemieniuk RAC, Bartoszko JJ, Díaz Martinez JP, Kum E, Qasim A, Zeraatkar D, et al. Antibody and cellular therapies for treatment of COVID-19: A living systematic review and network meta-analysis. BMJ. 2021;374:n2231. https://doi.org/10.1136/ bmj.n2231

PMid:34556486

8. Han H, Ma Q, Li C, Liu R, Zhao L, Wang W, et al. Profiling serum cytokines in COVID-19 patients reveals IL-6 and IL-10 are disease severity predictors. Emerg Microbes Infect. 2020;9(1):1123-30. https://doi.org/10.1080/22221751.2020.1770129 PMid:32475230

9. Shaikh FS, Aldhafferi N, Buker A, Alqahtani A, Dey S, Abdulhamid $\mathrm{S}$, et al. Comorbidities and risk factors for severe outcomes in COVID-19 patients in Saudi Arabia: A retrospective cohort study. J Multidiscip Healthc. 2021;14:2169-83. https:// doi.org/10.2147/JMDH.S31788

PMid:34408431

10. Merza MY, Hwaiz RA, Hamad BK, Mohammad KA, Hama HA, Karim AY. Analysis of cytokines in SARS-CoV-2 or COVID-19 patients in Erbil city, Kurdistan region of Iraq. PLoS One. 2021;16(4):e0250330. https://doi.org/10.1371/journal. pone. 0250330

PMid:33914789

11. Liu QQ, Cheng A, Wang Y, Li H, Hu L, Zhao X, et al. Cytokines and their relationship with the severity and prognosis of Coronavirus disease 2019 (COVID-19): A retrospective cohort study. BMJ Open. 2020;10(11):e041471. https://doi.org/10.1136/ bmjopen-2020-041471

PMid:33257492

12. Guan WJ, Liang WH, He JX, Zhong NS. Cardiovascular comorbidity and its impact on patients with COVID-19. Eur Respir J. 2020;55(6):2001227. https://doi. org/10.1183/13993003.01227-2020 PMid:32341104

13. Zhou Y, Yang Q, Chi J, Dong B, Lv W, Shen L, et al Comorbidities and the risk of severe or fatal outcomes associated with Coronavirus disease 2019: A systematic review and meta-analysis. Int J Infect Dis. 2020;99:47-56. https://doi. org/10.1016/j.jijd.2020.07.029

PMid:32721533

14. McElvaney OJ, McEvoy NL, McElvaney OF, Carroll TP, Murphy MP, Dunlea DM, et al. Characterization of the inflammatory response to severe COVID-19 IIIness. Am J Respir Crit Care Med. 2020;202(6):812-21. https://doi.org/10.1164/ rccm.202005-15830C PMid:32584597

15. Fathi M, Vakili K, Sayehmiri F, Mohamadkhani A, Hajiesmaeili M, Rezaei-Tavirani $\mathrm{M}$, et al. The prognostic value of comorbidity for the severity of COVID-19: A systematic review and metaanalysis study. PLoS One. 2021;16(2):e0246190. https://doi. org/10.1371/journal.pone.0246190 PMid:33592019

16. Rabaan AA, Al-Ahmed SH, Muhammad J, Khan A, Sule AA Tirupathi $\mathrm{R}$, et al. Role of inflammatory cytokines in COVID-19 patients: A review on molecular mechanisms, immune functions, immunopathology and immunomodulatory drugs to counter cytokine storm. Vaccines. 2021;9(5):436. https://doi.org/10.3390/vaccines9050436 PMid:33946736

17. Del Valle DM, Kim-Schulze S, Huang HH, Beckmann ND, Nirenberg S, Wang B, et al. An inflammatory cytokine signature predicts COVID-19 severity and survival. Nat Med. 2020;26(10):1636-43. https://doi.org/10.1038/ s41591-020-1051-9

PMid:32839624 